\section{Group theory}

Classical Groups for Physicists. By Brian G. Wybourne. Pp. xvi +415 . (Wiley: New York and London 1974.) $£ 10.60$.

THIS is a fine introduction to the group theoretical method in modern physics. During the past twenty-five years, the significance of symmetry transformations in describing physical phenomena has come to be recognised more and more and with it the use of group theory -and particularly the theory of Lie groups, due to the work of Wigner, Racah and others. This volume gives an exposition of Lie group theory for physicists following the traditional treatment of Weyl and Cartan as modified by the work of Dynkin and the Russian School.

The book divides into two major parts. The first presents a detailed exposition of the principal features of Lie groups and algebras and their topological structures, leading up to the Cartan-Weyl classification. Diagrammatic techniques of Dynkin are used to construct simple Lie algebras, and concepts of weights, Casimir invariants, and Clebsch-Gordon coefficients are discussed in detail. The discussion is mostly carried through for compact groups though there is a brief section on the non-compact $\mathrm{SU}(1,1)$. This portion of the book is written very much from a physicist's point of view-that is to say, principal concepts are introduced, results stated though not always proved with the emphasis being very much on ideas and the methodology rather than on rigour. I thoroughly approve of the approach-I only wish this part of the book was longer.

The second part treats the group theory of three topics in detail-the isotropic harmonic oscillator, the hydrogen atom and the shell structure in nuclear theory. There is an excellent bibliography.

I would recommend the book for postgraduate students in nuclear theory and high energy physics as a selfcontained introduction to the advanced ideas and techniques.

\section{Abdus Salam}

\section{Intelligent beings}

The Development of Mind. By A. J. P. Kenny, H. C. Longuet-Higgins, J. R. Lucas and C. D. Waddington. Pp. 152. (Gifford Lectures 1972/1973.) (Edinburgh University: Edinburgh, April 1974.) £2.25.

THE traditional Gifford Lecture, with some notable person putting forward a synthesis of his views on natural theology, is a well established part of the British intellectual scene. For two recent winters, however, something different has been tried: a group of four people have shared the lectures, and at each session one person gave an opening statement, and there was then discussion between the four. Although each man is widely talented, they could be labelled as specialists in artificial intelligence, philosophy, theology, and biology respectively: and this volume reports the second series of such lectures.

On the whole, the title is taken as referring to the appearance of minds in the course of evolution: not in the other possible sense of the devclopment of a mind from that of the baby to that of the Gifford Lecturer. There are some cursory references to the latter problem, but on the whole the assumption is taken that "there is overwhelming evidence that our most primitive skills are inborn". The discussion concentrates mostly therefore on the view of the world we ought to have if evolution has given rise to creatures possessing our capacities: problems in fact not too dissimilar from those handled by Monod in Chance and Necessity, and that book is mentioned several times. By contrast with a book like Monod's, one naturally does not get a unified and single point of view in all its complexity: the main merit of this kind of attack is rather that any overemphasis by one lecturer can instantly be picked up by another. Thus for example the argument that language is difficult to explain by natural selection, because it is only of benefit when more than one person has it, is immediately countered by the argument that we only have to explain a series of small steps in improving communication, rather than the sudden appearance of a complete complex syntax. For those who want the balance and interaction of the various points of view represented, this will in some ways be a more satisfying book than that of Monod. Probably one should not lay down that all future Gifford Lectures should be of this type: but it was worth the attempt on this occasion.

Reaction to lectures on natural theology is bound to be a personal matter: but in two ways this volume fails to speak to my condition. First, the emphasis is on the processes which produce mind and not upon its nature, and this is linked with a silent assumption that all human beings have the kind of minds which can be heard discussing in Oxford and Edinburgh common rooms. Yet the outburst of studies of the behaviour of the developing child, and for that matter of adults with a rather different type of mind from the academic one, make one a bit doubtful of the generality of this kind of discussion. Our ancestors looked at the species which now exist and could see no way to explain thes other than by special creation: anc there is something of the same flavour about these discussions which take th mind as an unanalysed given, without considering development within the individual. To psychologists therefore, whose professional blinkers forbid them to take for granted what the mind is and what it does, this kind of discussion is bound to seem curiously old fashioned and irrelevant.

This kind of reaction leads on to another at a more human level. The pressing problems of natural theology seem to some psychologists to lie, not in the origin of species including oursclves, but in the problems which a human being may face in achieving a stable and satisfactory way of organising his mind, in the existence of alternative ways of doing so, in the need to change from one way to another as circumstances change, and in the difficulties in doing so once some mode of reaction has been established in an earlier situation. In the older, and doubtless outworn, language, these are the problems of the consciousness of $\sin$ and the experience of redemption, rather than those of the creation of the world, and perhaps they might be regarded as outside the field of the Gifford Lectures. They can, however, be the subject of rational discussion, quite apart from the particular solutions offered to them, and some of us would like to read a similar volume on that line even more than this one.

Donald E. BroadBent

\section{Where sediments build up}

Depositional Sedimentary Environments, with Reference to Terrigenous Clastics. By H. E. Reineck and I. B. Singh. Pp. xvi +439 . (Springer-Verlag: Berlin and New York, 1973.) DM108; $\$ 44.30$.

IN recent years there has been a spate of books published in the field of sedimentary geology. These have included general texts on the origin and petrography of sedimentary rocks and processes of sedimentation, and many dealing with specific sedimentary environments. The authors of this volume are to be congratulated on compiling and analysing all the major modern sedimentary environments in which terrigenous clastic sediments are de posited. The potential scope of the subject is so vast, yet the authors have succeeded in summarising it in a most readable manner. To this end, most of the information can otherwise only be seen in journals, so the book should provide both professional geologists and students with a commendable review of depositional environments.

The first part of the book deals 